14.03

\title{
Терагерцевый отклик от биоткани как основа диагностики и лечения в персонифицированной медицине
}

\author{
() Н.Т. Баграев, ${ }^{1}$ Л.Е. Клячкин,, А.М. Маляренко, ${ }^{1}$ К.Б. Таранец ${ }^{2}$ \\ ${ }^{1}$ Физико-технический институт им. А.Ф. Иоффре РАН, \\ 194021 Санкт-Петербург, Россия \\ ${ }^{2}$ Санкт-Петербургский политехнический университет Петра Великого, \\ 195251 Санкт-Петербург, Россия \\ e-mail: constanttaranets@gmail.com
}

Поступило в Редакцию 16 января 2020 г.

В окончательной редакции 21 февраля 2020 г.

Принято к публикации 21 февраля 2020 г.

\begin{abstract}
Предложен спектрометр на основе кремниевых наносандвичей (КНС) для решения задач персонифицированной медицины. Структуры кремниевого наносандвича (КНС) сочетают свойства терагерцевого (THz) излучателя и приемника THz-отклика от биоткани. Продемонстрировано, что регистрация вольт-амперных характеристик $(\mathrm{BAX})$ КНС-структуры позволяет анализировать спектральный состав $\mathrm{THz}-\mathrm{otклика} \mathrm{от}$ биоткани и таким образом определять относительный вклад различных белков и аминокислот, входящих в состав олигонуклеотидов ДНК и их соединений. При этом видны явные преимущества предложенной методики, поскольку THz-отклик может быть зарегистрирован непосредственно от живой биоткани, что может составить основу для экспресс-анализа олигонуклеотидов ДНК. Дальнейшее изучение особенностей поведения спектральных пиков ВАХ КНС представляет большой интерес для методов персонифицированной диагностики и лечения, что продемонстрировано на примере тестирования различных контрольных групп испытуемых.
\end{abstract}

Ключевые слова: кремниевый наносандвич, терагерцевое излучение, вольт-амперная характеристика, ДНК.

DOI: $10.21883 /$ JTF.2020.09.49682.18-20

\section{Введение}

Терагерцевое $(\mathrm{THz})$ излучение охватывает диапазон $100 \mathrm{GHz}-30 \mathrm{THz}$ (длины волны $3 \mathrm{~mm}-10 \mu \mathrm{m}$ ), т.е. коротковолновую часть миллиметрового диапазона, весь субмиллиметровый и дальний (длинноволновый) инфракрасный (ИК) диапазоны длин волн. Особенностью THzквантов излучения является их низкая энергия, из-за чего оно является неионизирующим, а также его стимулирующий эффект при протекании важнейших биологических реакций даже несмотря на ослабление его интенсивности в десятки тысяч раз при проникновении на глубину в несколько сотен микрон от поверхности кожи. Важным является факт, что все белки и их соединения излучают и поглощают в THz-диапазоне. К сожалению, THz-излучение не проникает сквозь атмосферу Земли, из-за чего все существующие его источники являются искусственными. Более того, они представляют собой громоздкую и дорогостоящую аппаратуру, подобную лазерам на свободных электронах, лампам бегущей волны или термическим источникам слабого некогерентного излучения, а для детектирования терагерцевого излучения используются охлаждаемые жидким гелием болометры с низким уровнем шума. Однако в последнее время прогресс в области нанотехнологии полупроводников и высокотемпературных сверхпроводников сделал возможным получение компактных твердотельных приборов, которые способны излучать и детектировать в терагерцевом диапазоне длин волн [1,2]. Таким образом, прежде недоступная область спектра стала практически экспериментально реализуемой и таит в себе огромный потенциал применений.

THz-излучение свободно проходит через бумагу, дерево, некоторые строительные конструкции, пластики, керамику, а также верхние слои кожи и одежду человека. В ряде европейских стран гигагерцовые волны используются для просвечивания пассажиров и груза в аэропортах вместо вредного для здоровья рентгеновского излучения. Еще одним перспективным направлением является использование терагерцевого излучения для идентификации личности, поскольку структура олигонуклеотидов ДНК взаимосвязана с конкретной частотой в терагерцевом диапазоне электромагнитного спектра излучения (поглощения). В настоящей работе впервые предложено рассмотреть возможности для персональной идентификации с помощью анализа вольт-амперной характеристики (BAX) THz-излучателя в условиях отражения THz-излучения от биообъекта.

\section{1. Материалы и методы}

Экспериментальная установка состоит из источника THz-излучения, источника стабилизированного тока (Keithley 6221) и нановольтметра (Agilent 34420A). Синхронизация производилась с помощью программы National Instruments Lab View. Используемый диапазон 


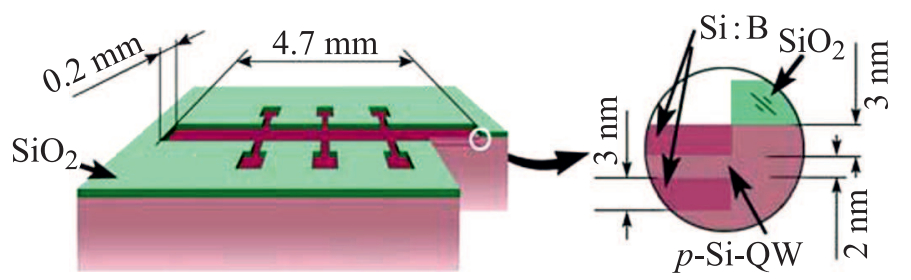

$b$

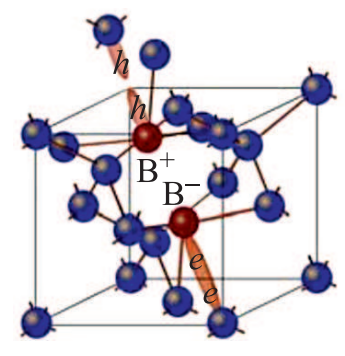

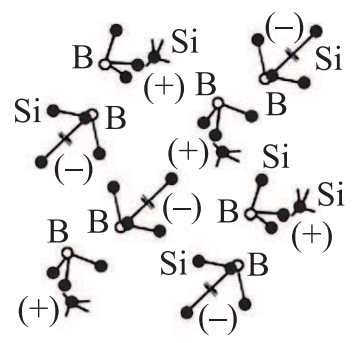

Рис. 1. $a-$ схема КНС с характерными размерами; $b-$ дипольный тригональный центр бора $\left(\mathrm{B}^{+}-\mathrm{B}^{-}\right)$с отрицательной корреляционной энергией и цепочки дипольных центров бора в $\delta$-барьерах, ограничивающих $p$-Si-QW.

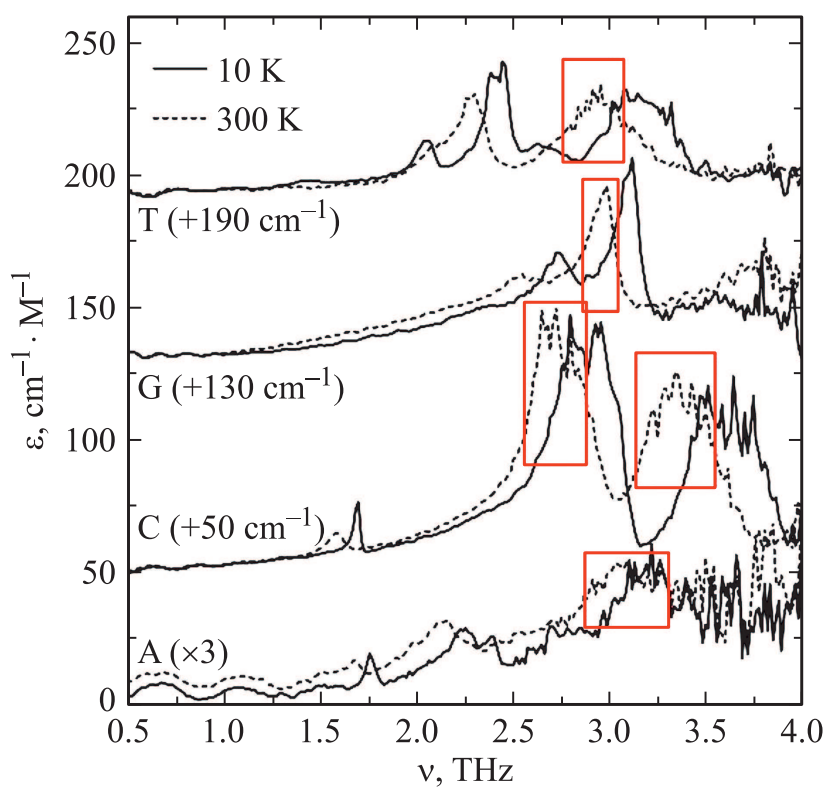

Pис. 2. Спектральная зависимость коэффициента поглощения белков: аденина (A), цитозина $(\mathrm{C})$, гуанина $(\mathrm{G})$ и $(\mathrm{T})$, полученный при $10 \mathrm{~K}$ (жирная линия) и $300 \mathrm{~K}$ (штриховая линия) [7].

стабилизированного тока $-[-3.5 ; 3.5] \mu \mathrm{A}$ с шагом $0.01 \mu \mathrm{A}$, каждая точка измерялась 20 раз, после чего происходило усреднение, которое и отражено на представленных ниже зависимостях.

В качестве источника THz-излучения использовался кремниевый наносандвич (КНС), который представляет собой сверхузкую кремниевую квантовую яму $p$-типа $(p$-SiQW), ограниченную $\delta$-барьерами, сильно легированными бором $\left(5 \cdot 10^{21} \mathrm{~cm}^{-3}\right)$ на поверхности $n$-Si (100), в которой достигается высокая подвижность носителей (рис. 1) [3, 4]. Данные $p$-Si-QW формируются на $n$-Si 100) подложках в процессе предварительного окисления и последующей кратковременной диффузии бора из газовой фазы $[3,5]$. Было показано, что атомы бора в $\delta$-барьерах образуют тригональные дипольные центры $\left(\mathrm{B}^{+}-\mathrm{B}^{-}\right)$вследствие negative-U-реакции: $2 \mathrm{~B}^{0} \rightarrow \mathrm{B}^{+}+\mathrm{B}^{-}[5]$, кристаллографически ориентированные последовательности которых формируют крае- вые каналы, ответственные за проводимость в $p$-Si-QW. Двумерная плотность дырок определялась с помощью регистрации полевых холловских зависимостей,

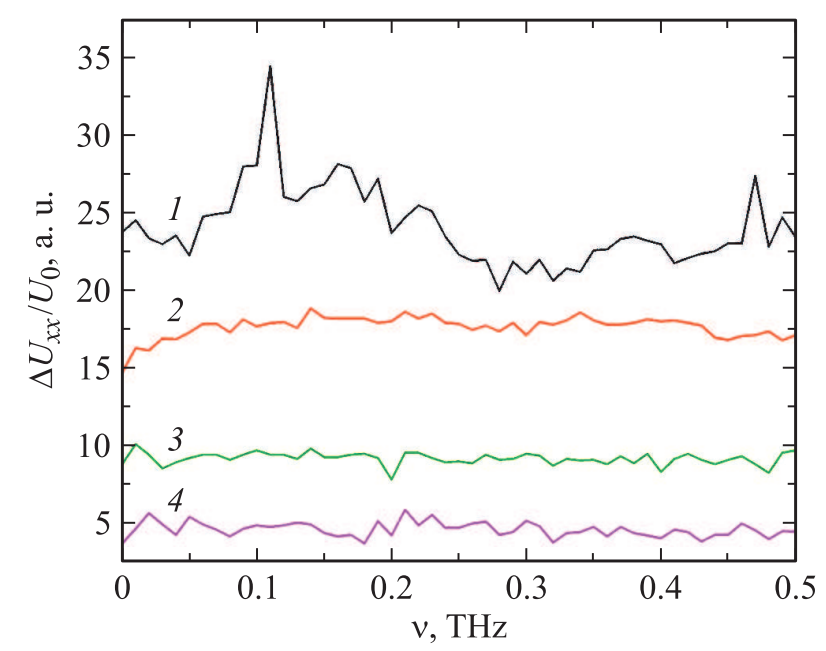

Рис. 3. Терагерцевый отклик большого пальца левой руки (1), большого пальца правой руки (2), груди (3) (+5 rel.u.) и щитовидной железы (4) одного из испытуемых.

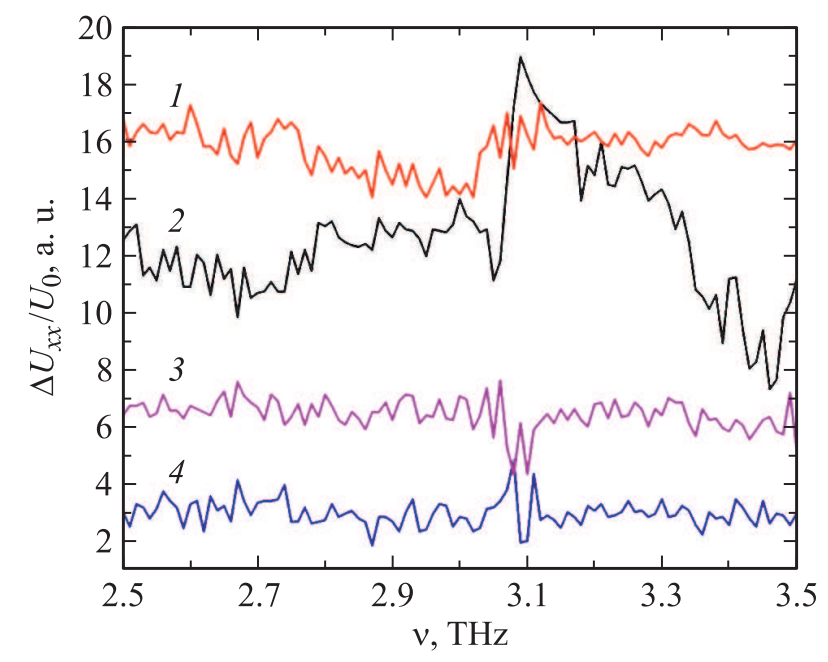

Рис. 4. Терагерцевый отклик большого пальца правой руки (1), большого пальца левой руки (2), груди (3) (+5 rel.u.) и щитовидной железы (4) одного из испытуемых. 


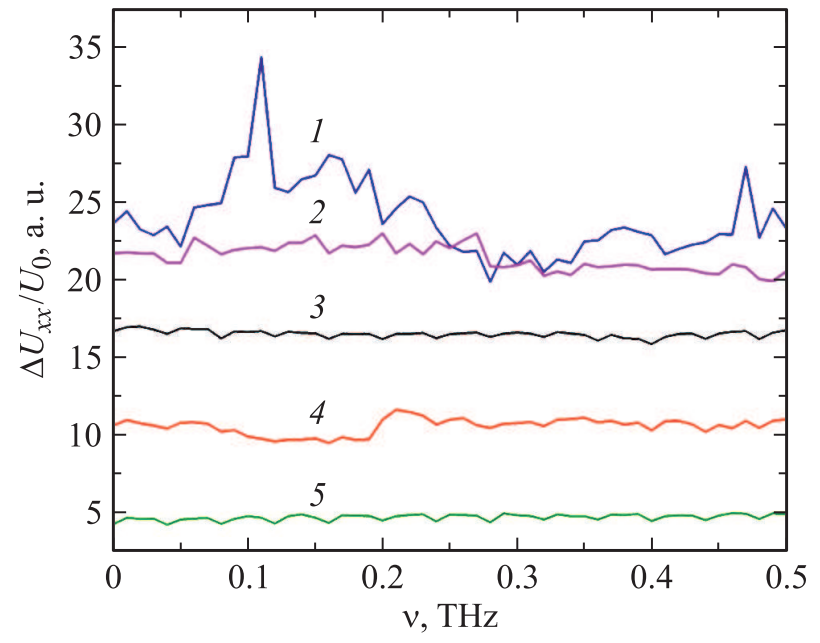

Рис. 5. Терагерцевый отклик большого пальца левой руки (1), (2) (+15 rel. u.), (3) (+10 rel. u.), (4) (+5 rel. u.) и (5) у разных испытуемых.

$3 \cdot 10^{13} \mathrm{~m}^{-2}[4]$. Кроме того, было показано, что краевые каналы $p-\mathrm{Si}-\mathrm{QW}$ являются в условиях продольного то-

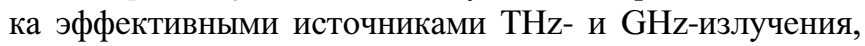
обусловленного наличием negative-U дипольных центров бора (рис. 1) [6]. Характеристиками излучения можно управлять как при помощи варьирования величиной стабилизированного тока исток-сток, так и добавлением в структуру микрорезонаторов на различные длины волн. Наличие THz- и GHz-излучения из КНС было подтверждено с помощью различных экспериментальных методик [3]. Причем использование ИК-фурье спектрометра показало, что, варьируя характеристиками микрорезонаторов, встроенных в краевые каналы $\mathrm{Si}-\mathrm{QW}$, можно

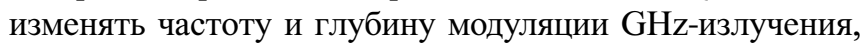
модулирующего THz-отклик биообъекта [3].

В ходе эксперимента излучатель, который одновременно являлся и приемником $\mathrm{THz}-\mathrm{GHz}-о$ отлика от биообъекта, направлялся на исследуемую область и находился на расстоянии около $1 \mathrm{~cm}$ от его поверхности. Таким образом, прибор работал в режиме балансного фотоприемника. В основе механизма генерации и приема $\mathrm{THz}-\mathrm{GHz}-$ излучения лежит квантовый эффект Фарадея [6].

\section{2. Результаты и обсуждение}

Всего было изучено пять добровольно испытуемых. Изучались различные органы (левый и правый большие пальцы, грудь и щитовидная железа) на предмет наличия воспроизводимости различных частот и интенсивности излучения как у одного человека, так и наличие корреляций между разными людьми для одних и тех же органов. Особое внимание уделялось диапазону 2.-3.5 THz, который соответствует спектрам излучения олигонуклеотидов ДНК [7], отражая особенности THz-излучения пар
G-C и A-T (рис. 2), а также гигагерцевой части спектра, в частности в области $160 \mathrm{GHz}$, которая наиболее часто является модулирующей частотой $\mathrm{THz}-о$ оклика от биообъектов. Следует отметить, что данное значение соответствует частоте реликтового излучения.

На рис. 3 и 4 представлен отклик в различных частотных диапазонах, полученный от различных органов одного из испытуемых. Ярко выраженной является разница по амплитуде сигнала между большими пальцами и щитовидной железой и грудью. Существенные различия между большими пальцами может быть обусловлено различиями в структуре кровеносных сосудов для различных половин человеческого тела. Кроме того, стоит отметить характерные особенности в диапазоне частот, ответственных за отклик олигонуклеотидов ДНК (рис. 4). При более детальном изучении данной обла-

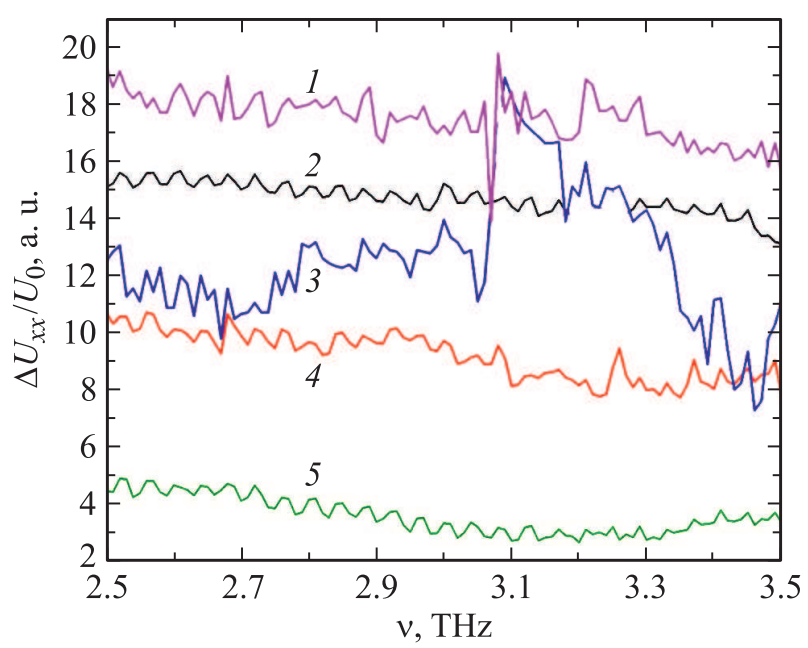

Рис. 6. Терагерцевый отклик большого пальца левой руки (1) (+15 rel. u.), (2) (+10 rel. u.), (3), (4) (+5 rel. u.) и (5) у разных испытуемых.

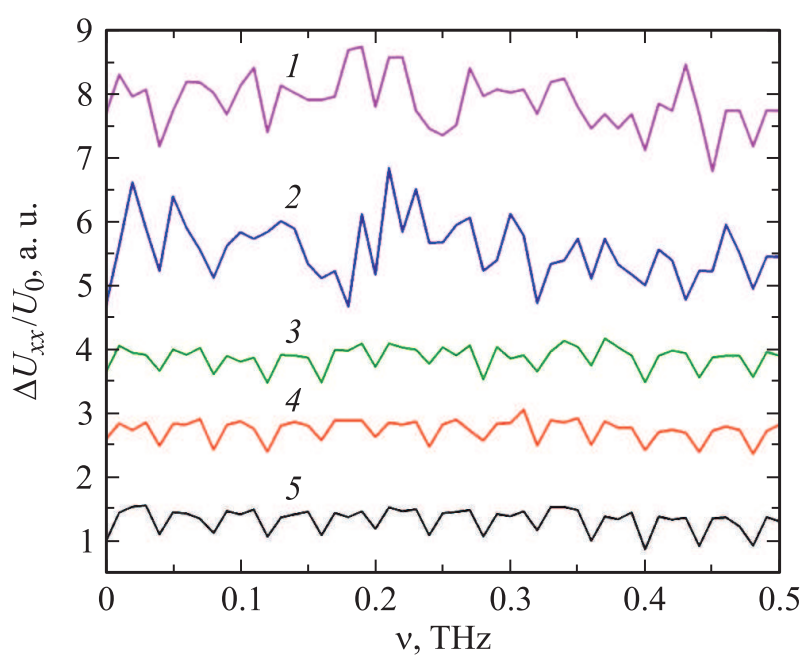

Рис. 7. Терагерцевый отклик щитовидной железы (1), (2) (+10 rel. u.), (3) (+20 rel. u.), (4) (+10 rel. u.) и (5) у разных испытуемых. 


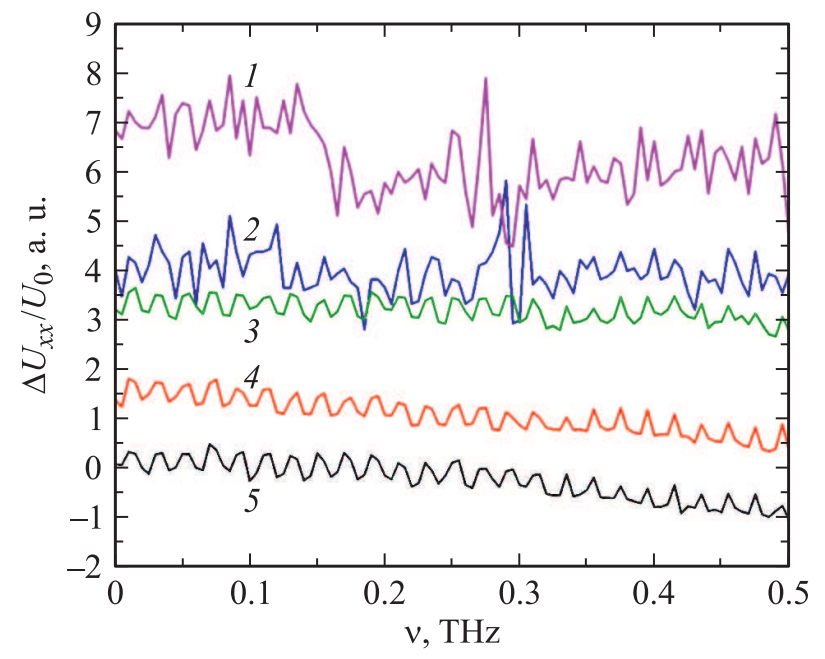

Рис. 8. Терагерцевый отклик щитовидной железы (1), (2) (+10 el. u.), (3) (+20 rel. u.), (4) (+10 rel. u.) и $(5)$ у разных испытуемых.

сти возможно удастся определить положение пиков с доминирующим количеством пар $\mathrm{C}-\mathrm{G}$ и $\mathrm{A}-\mathrm{T}$. Таким образом, THz-отклик при облучении различных органов испытуемого может быть использован в качестве основы идентификации его личности.

Помимо этого, на рис. 5-8 сравнивались отклики щитовидной железы и большого пальца. На всех зависимостях присутствует по три кривых с повторяющимся паттерном, природу которого еще предстоит выяснить. Однако уже сейчас можно дать интерпретацию данной особенности как отклик нервных клеток. Особенности в области частот олигонуклеотидов ДНК (рис. 6, 8) также присутствуют.

\section{Заключение}

Представлен спектрометр на основе КНС, сочетаю-

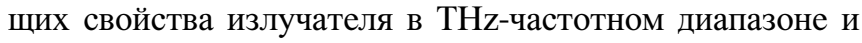
приемника отклика THz-излучения от биоткани. КНС, который был получен в рамках планарной кремнивой технологии на поверхности $n-\mathrm{Si}(100)$, представляет собой сверхузкую кремниевую квантовую яму $p$-типа $(p$-Si-QW), ограниченную $\delta$-барьерами, сильно легированными бором $\left(5 \cdot 10^{21} \mathrm{~cm}^{-3}\right)$. Было показано, что при пропускании тока исток-сток краевые каналы, состоящие из дипольных центров бора с отрицательной корреляционной энергией, являются эффективными источниками и приемниками THz-излучения, характеристиками которого можно управлять благодаря микрорезонаторам, встроенным в краевые каналы $p$-Si-QW .

Тестирование различных контрольных групп испытуемых показало, что регистрация ВАХ КНС-структуры в условиях THz-отклика от биоткани испытуемого позволяет анализировать его спектральный состав и таким образом проводить экспресс-анализ относительного вклада различных белков и аминокислот, входящих в состав олигонуклеотидов ДНК и их соединений. Дальнейшее изучение особенностей поведения спектральных пиков BAX КНС представляет большой интерес для методов персонифицированной диагностики и лечения.

\section{Финансирование работы}

Работа выполнялась в рамках программы исследований, запланированных в Физико-техническом институте им. А.Ф. Иоффе РАН.

\section{Соблюдение этических стандартов}

Все процедуры, выполненные в исследовании с участием людей, соответствуют этическими стандартами институционального и/или национального комитета по исследовательской этике и Хельсинкской декларации 1964 года и ее последующим изменениям или сопоставимым нормам этики.

От каждого из включенных в исследование участников было получено информированное добровольное согласие.

\section{Конфликт интересов}

Авторы заявляют, что у них нет конфликта интересов.

\section{Список литературы}

[1] Humphreys K., Loughran J.P., Gradziel M., Lanigan W., Ward T., Murphy J.A., O'Sullivan C. // The 26th Annual International Conference of the IEEE Engineering in Medicine and Biology Society. IEEE. 2004. Vol. 1. P. 1302-1305.

[2] Woodward R.M., Cole B.E., Wallace V.P., Pye R.J., Arnone D.D., Linfield E.H., Pepper M. // Phys. Medicine Biology. 2002. Vol. 47. N 21. P. 3853.

[3] Баграев Н.Т., Клячкин Л.Е., Маляренко А.М., Новиков Б.А. // Биотехносфера. 2015. № 5 (41). С. 67-79.

[4] Bagraev N.T., Galkin N.G., Gehlhoff W., Klyachkin L.E., Malyarenko A.M. // J. Phys.: Condens. Matter. 2008. Vol. 20. P. 164202.

[5] Bagraev N.T., Mashkov V.A., Danilovsky E.Yu., Gehlhoff W., Gets D.S., Klyachkin L.E., Kudryavtsev A.A., Kuzmin R.V., Malyarenko A.M., Romanov V.V. // Appl. Magn. Resonance. 2010. Vol. 39. N 1-2. P. 113-135.

[6] Bagraev N.T., Grigoryev V.Yu., Klyachkin L.E., Malyarenko A.M., Mashkov V.A., Romanov V.V. // ФТП. 2016. T. 50. Вып. 8. С. 1047-1054. [Bagraev N.T., Grigoryev V.Yu., Klyachkin L.E., Malyarenko A.M., Mashkov V.A., Romanov V.V. // Semiconductors. 2016. Vol. N 8. P. 1025-1033.]

[7] Fischer B.M., Walther M., Jepsen P.U. // Phys. Medicine Biology. 2002. Vol. 47. N 21. P. 3807. 